\title{
PENGARUH BIAYA KUALITAS TERHADAP PERTUMBUHAN PENJUALAN DAN PROFITABILITAS
}

\author{
(Studi Empiris Pada Perusahaan Daerah Air Minum Tahun 2015-2017) \\ ${ }^{1}$ Muhammad Iqbal Kusmana, ${ }^{2}$ Muhammad Dahlan, ${ }^{3}$ Dede Abdul Hasyir \\ ${ }^{1}$ Program Studi Magister Akuntansi Universitas Padjajaran \\ ${ }^{2,3}$ Dosen Program Studi Akuntansi Universitas Padjajaran \\ Email: iqbal533@ymail.com
}

\begin{abstract}
The study aims to analyze the effect of quality costs on sales growth and profitability in regional drinking water companies (PDAMs). This study uses a quantitative approach. The population in this study is quality costs in 391 PDAMs throughout Indonesia with a sample of 325 PDAMs. The data used is annual data from the realization of quality costs, sales growth rates, and profit margins for three years, namely from 2015 to 2017. The results of this study indicate that quality costs have a significant positive effect on PDAM sales growth, with the percentage of influence equal to $66.7 \%$, while the remaining $33.3 \%$ is influenced by other factors not observed in this study and quality costs have a significant positive effect on PDAM profitability, with a percentage effect of 59.5\%, while the remaining $40.5 \%$ is influenced by other factors not observed in this study.
\end{abstract}

Keywords: Quality Costs, Sales Growth, Profitability

\begin{abstract}
Abstrak
Penelitian bertujuan untuk menganalisis pengaruh biaya kualitas terhadap pertumbuhan penjualan dan profitabilitas pada perusahaan daerah air minum (PDAM). Penelitian ini menggunakan pendekatan kuantitatif. Populasi dalam penelitian ini yaitu biaya kualitas di 391 PDAM seluruh Indonesia dengan sampel sebanyak 325 PDAM. Data yang dipergunakan merupakan data per tahun dari realisasi biaya kualitas, tingkat pertumbuhan penjualan, dan profit margin selama tiga tahun yaitu dari tahun 2015 sampai dengan tahun 2017. Hasil penelitian ini menunjukan bahwa biaya kualitas berpengaruh positif signifikan terhadap pertumbuhan penjualan PDAM, dengan persentase pengaruh sebesar $66,7 \%$, sedangkan sisanya sebesar 33,3\% dipengaruhi oleh faktor lain yang tidak diamati dalam penelitian ini dan biaya kualitas berpengaruh positif signifikan terhadap profitabilitas PDAM, dengan persentase pengaruh sebesar 59,5\%, sedangkan sisanya sebesar 40,5\% dipengaruhi oleh faktor lain yang tidak diamati dalam penelitian ini.
\end{abstract}

Kata Kunci : Biaya Kualitas, Pertumbuhan Penjualan, Profitabilitas 


\section{PENDAHULUAN}

Air merupakan faktor yang sangat penting dalam kehidupan manusia dan seluruh mahluk hidup. Keberadaan air memberikan kehidupan bagi seluruh mahluk hidup, kususnya manusia air menjadi sesuatu yang menemani semua aktivitas manusia. Mengingat betapa pentingnya air bagi kehidupan manusia tentunya air bersih atau air minum harus dikelola dengan baik, agar layak untuk digunakan, dikonsumsi dan menjaga kelestariannya.

Di Indonesia segala bidang produksi yang penting bagi negara dan mempengaruhi hajat hidup orang banyak dalam pengelolaannya akan dikuasai oleh negara. pengelolaan air baku di indonesia itu sendiri di kelola oleh perusahaan daerah air minum (PDAM) sebagai sektor publik, dimana organisasi publik adalah organisasi yang didirikan dengan tujuan memberikan pelayanan kepada masyarakat. Orientasi organisasi publik adalah untuk melayani masyarakat. Mahsun (2009: 163) menyatakan bahwa organisasi publik dapat dibedakan menjadi dua, yaitu pure nonprofit organizations dan quasi nonprofit organizations. Bila dilihat dari kategorinya PDAM tergolong dalam quasi nonprofit organization yaitu organisasi publik yang menjual barang atau jasa untuk melayani masyarakat dan memperoleh keuntungan. Bila dilihat dari kategorinya PDAM tergolong dalam quasi nonprofit organization yaitu organisasi publik yang menjual barang atau jasa untuk melayani masyarakat dan memperoleh keuntungan.

Berdasarkan hasil penilaian kinerja PDAM 2017 yang dilakukan BPPSPAM terhadap 373 PDAM di Indonesia sejumlah 222 PDAM berkategori sehat (59,5\%), 99 PDAM kurang sehat $(26,5 \%)$, dan 66 PDAM sakit (14\%). Berdasarkan data tersebut terungkap bahwa hanya $(59,5 \%)$ yang berada dalam kategori sehat, tentunya hal ini bukan merupakan catatan yang baik bagi Perusahaan Daerah Air Minum (PDAM) yang memiliki peran ganda yakni berorientasi untuk mencari laba, dan juga untuk mensejahterakan masyarakat.
Perusahaan Daerah Air Minum (PDAM) memiliki peran ganda yakni berorientasi untuk mencari laba, tetapi juga untuk mensejahterakan masyarakat. Oleh karena itu perlu adanya kajian akan biaya, pertumbuhan penjualan, profitabilitas dan faktor yang mempengaruhinya. Berdasarkan penelitian yang dilakukan (Winarto, 2015) menunjukkan bahwa keempat variabel biaya kualitas yaitu biaya pencegahan, biaya penilaian, biaya kegagalan internal dan biaya kegagalan eksternal memiliki pengaruh yang positif dan signifikan terhadap tingkat profitabilitas perusahaan hal ini benunjukan bilamana biaya kualitas dapat di kelola dengan baik maka dapat membantu PDAM memenuhi tuntutan sebagai pemasukan bagi daerah dan menurut (Lestari dan Hakim, 2014) Secara simultan atau bersama-sama biaya kualitas yang terdiri dari biaya pencegahan, biaya penilaian, biaya kegagalan internal, dan biaya kegagalan eksternal berpengaruh positif terhadap tingkat penjualan, hal ini menunjukan pengelolaan biaya kualitas selain dapat meningkatkan profitabilitas juga dapat membantu PDAM untuk menjalankan fungsinya sebagai pelayanan terhadap masyarakat dengan meningkatkan penjualan.

Pengendalian biaya kualitas, profitabilitas, dan pertumbuhan penjualan dapat dijadikan sebagai salah satu rujukan bagi pemerintah, pemerintah daerah dan PDAM serta para pemangku kepentingan (stakeholders) dalam menentukan kebijakan dan strategi dalam meningkatkan profitabilitas dan pengembangan Sistem Penyediaan Air Minum (SPAM), sehingga PDAM ke depannya mampu berkontribusi terhadap pemasukan daerah dan pemenuhan kebutuhan air minum masyarakat Indonesia yang memenuhi syarat kualitas, kuantitas dan kontinuitas. Berdasarkan permasalahan diatas, penulis tertarik untuk melakukan penelitian dengan mengambil judul "Pengaruh Biaya Kualitas Terhadap Pertumbuhan Penjualan Dan Profitabilitas (Studi Empiris Pada Perusahaan Daerah Air Minum)" 


\section{KAJIAN LITERATUR}

\subsection{Agency Theory}

Teori keagenan (agency theory) dikembangkan di tahun 1970-an terutama pada tulisan Jensen dan Meckling (1976) pada tulisan yang berjudul "Theory of the firm: Managerial behavior, agency costs, and ownership structure". Jensen dan Meckling (1976) menjelaskan hubungan keagenan sebagai "agency relationship as a contract under which one or more person (the principals) engage another person (the agent) to perform some service on their behalf which involves delegating some decision making authority to the agent". Atau dengan kata lain penulis menyimpulkan bahwa teori agensi merupakan sebuah konsep yang dapat menjelaskan dengan lebih baik dalam hubungan kontraktual antara principals dan agents. Pihak principals adalah pihak yang memberikan mandat kepada pihak lain, yaitu agent, untuk melakukan semua kegiatan atas nama principals dalam kapasitasnya sebagai pengambil keputusan.

\subsection{Biaya Kualitas}

Untuk menjalankan aktivitas produksi, sebuah perusahaan memerlukan biaya untuk menghasilkan barang atau jasa. Menurut (Hansen dan Mowen, 2006) mengungkapkan bahwa biaya adalah pengeluaran kas atau setara kas yang dapat memberikan manfaat bagi organisasi di masa yang akan datang, yang di ungkapkan sebagai berikut: "Cost is the cash or cash equivalent value sacrificed for goods and services that are expected to bring a current or future benefit to the organization."

Kriteria atau ukuran suatu kualitas bervariasi dan cenderung terus dapat berubah sepanjang waktu, oleh karena itu tidaklah mudah untuk mendefinisikan kualitas secara tepat. Kualitas itu sendiri menggambarkan karakteristik dari suatu produk seperti performance, dan keandalan. Menurut (Gaspersz, 2008) definisi kualitas secara strategik adalah sesuatu yang mampu memenuhi keinginan atau kebutuhan pelanggan.

Dalam menjalankan aktivitas-aktivitas yang telah dilakukan oleh perusahaan sehubungan dengan pengembangan kualitas suatu barang yang dihasilkan, perusahaan harus mengeluarkan biaya-biaya untuk melakukan aktivitas-aktivitas kualitasnya, yang disebut biaya kualitas untuk mempertahankan hasil produksinya. Maka perusahaan akan mengeluarkan biaya-biaya kualitas. Menurut Hansen \& Mowen (2006:11) didefinisikan biaya kualitas (cost of quality) adalah: "Biaya-biaya yang timbul karena atau mungkin telah terdapat produk yang buruk kualitasnya". Biaya kualitas pada perusahaanperusahaan umumnya masih mencapai $20-30 \%$ dari penjualan, sedangkan dikatakan tingkat biaya kualitas yang optimal adalah $2-4 \%$ dari penjualan.

Menurut Carter Usry yang (2006:198), komponen biaya kualitas terdiri dari: biaya pencegahan (Prevention costs), biaya penilaian (Appraisal costs), biaya kegagalan internal (Internal failure costs), dan biaya kegagalan eksternal (External failure costs)

\subsection{Profitabilitas}

$\begin{array}{cccr}\text { Tujuan utama } & \text { dari setiap } \\ \text { perusahaan adalah untuk mendapatkan }\end{array}$ profitabilitas semaksimal mungkin dengan meningkatkan kinerja tiap lini bagian dari perusahaan serta meningkatkan efisiensi dan efektifitas agar perusahaan dapat mampu bertahan, PDAM sebagai sektor publik yang masuk dalam kategori quasi nonprofit organizations memiliki dua kewajiban yakni melayani masyarakat dan menghasilkan profit yang berguna bagi pendapatan daerah. Pengertian profitabilitas menurut Sofyan Syafri Harahap (2005: 304): "Rasio rentabilitas atau disebut profitabilitas menggambarkan kemampuan perusahaan mendapatkan laba melalui kemampuan dan sumber yang ada seperti kegiatan penjualan, kas, modal, jumlah karyawan, jumlah cadangan, dan sebagainya. Rasio ini 
menggambarkan kemampuan perusahaan menghasilkan laba disebut Operaing ratio"

\subsection{Pertumbuhan Penjualan}

Sales growth dapat menggambarkan peningkatan penjualan dari tahun ke tahun lainnya. Semakin tinggi tingkat sales growth menunjukan semakin baik pula suatu perusahaan dalam menjalankan operasinya. Dengan mengetahui penjualan dari tahun sebelumnya, perusahaan dapat lebih mengoptimalkan sumber daya. Menurut Brigham dan Houston (2011:145), "perusahaan dengan penjualan yang relatif stabil dapat lebih aman memperoleh lebih banyak pinjaman dan menanggung beban tetap yang lebih tinggi dibandingkan dengan perusahaan yang penjualannya tidak stabil". Sedangkan Growth menurut Kasmir (2017:107) adalah sebagai berikut: "Rasio pertumbuhan (Growth Ratio) merupakan rasio yang menggambarkan kemampuan perusahaan mempertahankan posisi ekonominya di tengah pertumbuhan perekonomian dan sektor usahanya. Rasio pertumbuhan ini dilihat dari berbagai segi sales (penjualan), earning after tax (EAT), laba per lembar saham, dividen perlembar saham, dan harga pasar perlembar saham."

\section{METODE PENELITIAN}

\subsection{Jenis Penelitian}

Penelitian ini bertujuan untuk menganalisis biaya kualitas dan pengaruhnya terhadap pertumbuhan penjualan dan profitabilitas PDAM (Perusahaan Daerah Air Minum). Jenis data yang diambil dalam penelitian ini adalah data sekunder. Menurut Sugiyono (2010:141) mendefinisikan data sekunder adalah sebagain berikut: "Sumber sekunder adalah sumber data yang diperoleh dengan cara membaca, mempelajari dan memahami melalui media lain yang bersumber dari literatur, buku-buku, serta dokumen perusahaan". Penelitian ini menggunakan pendekatan kuantitatif, menurut Borg and Gall (1989) mengungkapkan bahwa penelitian kuantitatif disebut sebagai metode tradisional, positivisik, scientific, confirmatory, kuantitatif.

\subsection{Populasi dan Sample}

Populasi menurut Sugiyono (2010:115) adalah wilayah generalisasi yang terdiri atas objek/subjek yang mempunyai kualitas dan karakteristik tertentu yang ditetapkan oleh peneliti untuk dipelajari dan kemudian ditarik kesimpulannya. Atau dengan kata lain populasi adalah keseluruhan obyek yang karakteristiknya akan diuji. Populasi dari penelitian ini adalah perusahaan daerah air minum (PDAM) di seluruh Indonesia yang berjumlah 391 PDAM, dimana dibutuhkan data keuangan mengenai data biaya yang berkaitan dengan analisis biaya kualitas, pertumbuhan penjualan, dan profitabilitas. Selanjutnya sample penelitian menggunakan 325 PDAM, menurut Sugiyono (2011:81) sample adalah bagian dari jumlah dan karakteristik yang dimiliki oleh populasi tersebut. Dalam penelitian ini, pemilihan sampel dilakukan oleh penulis dengan menggunakan metode purposive sampling. Metode ini merupakan metode pengambilan sampel berdasarkan kriteria tertentu yang ditetapkan oleh peneliti secara objektif (Supramono 2004: 58). Teknik purposive sampling terdiri dari dua tipe, yaitu pemilihan sampel berdasarkan pertimbangan tertentu (judgment sampling) dan pemilihan sampel berdasarkan kuota (quota sampling) (Sekaran dan Bougie, 2017).

\section{HASIL DAN PEMBAHASAN PENELITIAN}

4.1 Persamaan Regresi Linear Sederhana Dari hasil perhitungan diperoleh output dan persamaan regresi linear sederhana sebagai berikut: 
Tabel 4.1. Koefisien Regresi Biaya Kualitas dan Pertumbuhan Penjualan

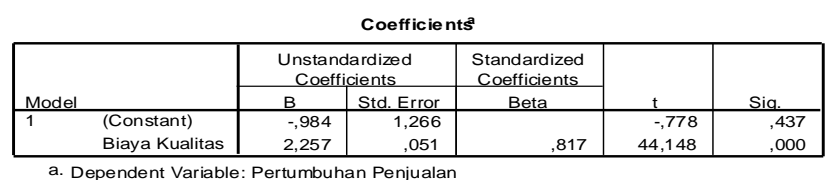

Adapun persamaan regresi linear sederhana sebagai berikut:

$\mathbf{Y}=\mathbf{a}+\mathbf{b X}$

Dimana: $\mathrm{Y}=$ Pertumbuhan

Penjualan

a $\quad=$ Nilai intersep

(konstanta)

$$
\begin{array}{ll}
\mathrm{X} & =\text { Biaya Kualitas } \\
\mathrm{b} & =\text { Koefisien Regresi }
\end{array}
$$

Dari hasil perhitungan diatas diperoleh nilai $a=-0,984$ dan nilai $b=2,257$. Dengan demikian diperoleh persamaan regresi linier sederhana sebagai berikut:

\section{Pertumbuhan Penjualan $=\mathbf{- 0 , 9 8 4}+\mathbf{2 , 2 5 7}$ Biaya Kualitas}

Persamaan diatas dapat diartikan sebagai berikut:

$\mathrm{a}=-0,984$; artinya jika biaya kualitas bernilai nol (0), maka pertumbuhan penjualan akan bernilai -0,984.

$\mathrm{b}=2,257$; artinya jika biaya kualitas meningkat sebesar satu satuan, maka pertumbuhan penjualan akan meningkat pula sebesar 2,257 satuan.

Tabel 4.2. Koefisien Regresi Biaya Kualitas dan Profitabilitas

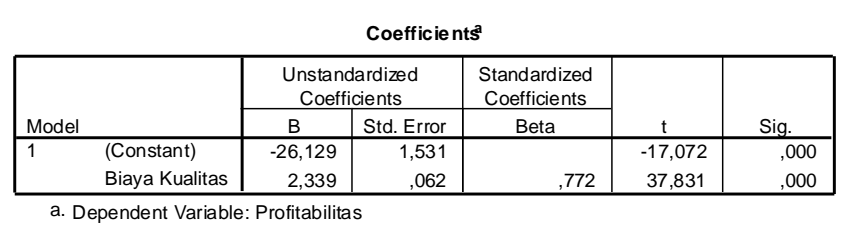

Adapun persamaan regresi linear sederhana sebagai berikut:

\section{$\mathbf{Y}=\mathbf{a}+\mathbf{b} \mathbf{X}$}

Dimana: $\mathrm{Y}=$ Profitabilitas

$$
\begin{array}{ll}
\mathrm{a} & =\text { Nilai intersep (konstanta) } \\
\mathrm{X} & =\text { Biaya Kualitas } \\
\mathrm{b} & =\text { Koefisien Regresi }
\end{array}
$$

Dari hasil perhitungan diatas diperoleh nilai $\mathrm{a}=-26,129$ dan nilai $\mathrm{b}=$ 2,339. Dengan demikian diperoleh persamaan regresi linier sederhana sebagai berikut:

\section{Profitabilitas $=-26,129+2,339$ Biaya Kualitas}

Persamaan diatas dapat diartikan sebagai berikut:

$a=-26,129$; artinya jika biaya kualitas bernilai nol (0), maka profitabilitas akan bernilai 0,984 .

$\mathrm{b}=2,339$; artinya jika biaya kualitas meningkat sebesar satu satuan, maka profitabilitas akan meningkat pula sebesar 2,339 satuan.

\subsection{Koefisien Determinasi ( $R$-square $)$}

Setelah diperoleh persamaan regresi, kemudian dilakukan perhitungan untuk mengetahui seberapa besar kemampuan biaya kualitas dalam menjelaskan naik turunnya

\begin{tabular}{|c|c|c|c|c|}
\hline \multicolumn{5}{|c|}{ Model Summary' } \\
\hline Model & $\mathrm{R}$ & R Square & $\begin{array}{l}\text { Adjusted } \\
\text { R Square }\end{array}$ & $\begin{array}{l}\text { Std. Error of } \\
\text { the Estimate }\end{array}$ \\
\hline 1 & $817^{a}$ & .667 & .667 & 37,91042 \\
\hline
\end{tabular}
profitabilitas yaitu dengan menggunakan rumus Koefisien Determinasi (KD) sebagai berikut:

\section{Tabel 4.3. Koefisien Determinasi}

Dimana :

$\mathrm{KD}=\left(\mathrm{r}_{\mathrm{xy}}\right)^{2} \times 100 \%$

$\mathrm{KD}=$ Koefisien determinasi

$\left(\mathrm{r}_{\mathrm{xy}}\right)^{2}=$ Koefisien korelasi product moment Sehingga:

$$
\begin{aligned}
\text { KD } & =r_{\mathrm{yx}}{ }^{2} \times 100 \% \\
= & (0,817)^{2} \times 100 \% \\
= & 66,7 \%
\end{aligned}
$$

Dari analisis diatas dapat dilihat bahwa kemampuan biaya kualitas dalam menjelaskan naik turunnya pertumbuhan penjualan sebesar $66,7 \%$, sedangkan sisanya sebesar $33,3 \%$ dipengaruhi oleh faktor lain yang tidak diamati dalam penelitian ini. 
Tabel 4.4. Koefisien Determinasi

\begin{tabular}{|l|r|r|r|r|}
\multicolumn{7}{|c|}{ Model Summ ary } \\
\hline Model & $\mathrm{R}$ & $\mathrm{R}$ Square & $\begin{array}{c}\text { Adjusted } \\
\text { R Square }\end{array}$ & $\begin{array}{c}\text { Std. Error of } \\
\text { the Estimate }\end{array}$ \\
\hline 1 &, $772^{\mathrm{a}}$ &, 595 &, 595 & 45,84903 \\
\hline
\end{tabular}

Dimana :

$\mathrm{KD}=\left(\mathrm{r}_{\mathrm{xy}}\right)^{2} \times 100 \%$

$\mathrm{KD}=$ Koefisien determinasi

$\left(\mathrm{r}_{\mathrm{xy}}\right)^{2}=$ Koefisien korelasi product moment

$$
\begin{aligned}
& \text { Sehingga: } \\
& \begin{aligned}
\text { KD } & =\mathrm{r}_{\mathrm{yx}}{ }^{2} \times 100 \% \\
& =(0,772)^{2} \times 100 \% \\
& =59,5 \%
\end{aligned}
\end{aligned}
$$

Dari analisis diatas dapat dilihat bahwa kemampuan biaya kualitas dalam menjelaskan naik turunnya profitabilitas sebesar 59,5\%, sedangkan sisanya sebesar 40,5\% dipengaruhi oleh faktor lain yang tidak diamati dalam penelitian ini.

\subsection{Pengujian Hipotesis (Uji-t)}

Pengujian yang dilakukan adalah uji parameter (uji korelasi) dengan menggunakan uji t-statistik. Hal ini membuktikan apakah terdapat pengaruh antara masing-masing variabel independen (X) dan variabel dependen (Y). Menurut Sugiyono (2013:250). Uji T melakukan penerimaan atau penolakan hipotesis dengan kriteria berikut ini (Ghozali, 2016) :

- Ho diterima: Jika $\mathrm{t}$ hitung $<\mathrm{t}$ tabel (sig.>0.05)

- Ho ditolak: Jika $\mathrm{t}$ hitung $>\mathrm{t}$ tabel (sig. $<0.05)$

Jika Ho diterima artinya menunjukkan bahwa koefisien regresi tidak signifikan dan secara parsial variabel independennya tidak berpengaruh signifikan terhadap variabel dependen. Apabila Ho ditolak menunjukkan koefisien regresi signifikan dan secara parsial variabel independen tersebut berpengaruh signifikan terhadap variabel dependen (Ghozali, 2016).

\begin{tabular}{|c|c|c|c|c|c|c|}
\hline & & & & & & \\
\hline & & \multicolumn{2}{|c|}{$\begin{array}{c}\text { Unstandardized } \\
\text { Coefficients }\end{array}$} & $\begin{array}{c}\text { Standardized } \\
\text { Coefficients }\end{array}$ & & \\
\hline \multicolumn{2}{|c|}{ Model } & $\mathrm{B}$ & Std. Error & Beta & $\mathrm{t}$ & Sig. \\
\hline \multirow{2}{*}{$\frac{\pi}{1}$} & (Constant) &,- 984 & 1,266 & &,- 778 & ,437 \\
\hline & Biaya Kualitas & 2,257 & 051 & 817 & 44,148 &, 000 \\
\hline
\end{tabular}

Dengan menggunakan program SPSS 19, diperoleh output sebagai berikut.
Tabel 4.5. Uji hipotesis (Uji t)

Berdasarkan Tabel 4.8, diperoleh nilai $\mathrm{t}_{\text {hitung }}$ sebesar 44,148 dengan nilai sig. ( $p$ value) sebesar 0,000. Dengan alpha $(\alpha)=5 \%$ atau 0,05 , maka diketahui bahwa sig. ( $p$-value) $<$ alpha atau 0,000 < 0,05 sehingga $\mathrm{H}_{0}$ ditolak yang menunjukkan bahwa biaya kualitas

\begin{tabular}{|c|c|c|c|c|c|c|}
\hline & 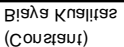 & $\begin{array}{r}-2.339 \\
-25_{3} 159\end{array}$ & 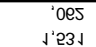 & $\$ 15$ & $\begin{aligned} 3 J^{\prime} 831 \\
-1 J^{\prime} 015\end{aligned}$ & "000 \\
\hline \multirow[t]{2}{*}{ WOqG } & & $B$ & 2+9 ElloL & $\bar{B} \Leftrightarrow \Phi^{9}$ & \multirow[t]{2}{*}{$f$} & \multirow[t]{2}{*}{ टाबं } \\
\hline & & $\begin{array}{r}\text { COGt } \\
\text { nuargh }\end{array}$ & 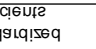 & 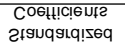 & & \\
\hline
\end{tabular}
berpengaruh positif signifikan terhadap pertumbuhan penjualan.

Tabel 4.6. Uji hipotesis (Uji t)

$$
\text { CosH!c!̣ Uiz }
$$

Berdasarkan Tabel 4.13, diperoleh nilai $t_{\text {hitung }}$ sebesar 37,831 dengan nilai sig. ( $p$ value) sebesar 0,000 . Dengan alpha $(\alpha)=5 \%$ atau 0,05, maka diketahui bahwa sig. ( $p$-value) $<$ alpha atau 0,000 < 0,05 sehingga $\mathrm{H}_{0}$ ditolak yang menunjukkan bahwa biaya kualitas berpengaruh positif signifikan terhadap profitabilitas.

\section{KESIMPULAN DAN REKOMENDASI 5.1 Kesimpulan}

Berdasarkan hasil penelitian dan pembahasan yang sudah dilakukan dapat disimpulkan bahwa :

1) Biaya kualitas berpengaruh positif signifikan terhadap pertumbuhan penjualan PDAM, dengan persentase pengaruh sebesar $66,7 \%$, sedangkan sisanya sebesar $33,3 \%$ dipengaruhi oleh faktor lain yang tidak diamati dalam penelitian ini. Semakin tinggi tingkat pertumbuhan penjualan menunjukan semakin baik pula perusahaan daerah air minum (PDAM) dalam menjaga kualitas produk atau jasa yang ditawarkannya dan juga semakin baik dalam menjalankan operasinya.

2) Biaya kualitas berpengaruh positif signifikan terhadap profitabilitas PDAM, dengan persentase pengaruh sebesar 
$59,5 \%$, sedangkan sisanya sebesar $40,5 \%$ dipengaruhi oleh faktor lain yang tidak diamati dalam penelitian ini. Seiringan dengan peningkatan penjualan mengakibatkan dampak positif pula pada profitabilitas perusahaan daerah air minum (PDAM), namun peningkatannya tidak sesignifikan kenaikan pertumbuhan penjualan dikarenakan masih tingginya tingkat kehilangan air perusahaan daerah air minum (PDAM) dikarenakan kebocoran atau buruknya akurasi meteran air.

\subsection{Rekomendasi}

Selain simpulan di atas, penulis juga mencoba memberikan saran-saran yang diharapkan dapat memberikan manfaaat melalui sumbangan pemikiran kepada perusahaan daerah air minum (PDAM) agar menjadi lebih baik di kemudian hari serta kepada para peneliti berikutnya agar penelitian yang akan datang akan jauh lebih baik lagi.

a) Untuk perusahaan daerah air minum (PDAM). Sebaiknya manajemen perusahaan secara berkala membuat atau melaporkan biaya-biaya yang dikeluarkan untuk mempertahakan atau meningkatkan kualitas, yaitu laporan biaya kualitas, karena informasi biaya kualitas akan memberikan berbagai macam manfaat, antara lain memberikan arahan untuk melakukan perbaikan-perbaikan yang, mengidentifikasi pemborosan dalam aktivitas yang tidak menambah nilai.

b) Untuk Penelitian Selanjutnya. Untuk penelitian berikutnya akan penulis menyarankan lebih baik lagi jika bisa mendapatkan kelengkapan data mengenai biaya kualitas yang lebih lengkap walaupun terkadang sulit di dapat karena biaya kualitas bersifat rahasia internal perusahaan. Bila mana dapat lebih lengkap dalam mengumpulkan data mengenai komponen biaya kualitas maka hasil penelitian akan lebih representatif.
Karena semakin banyak dan lengkap data mengenai biaya kualitasnya maka hasil penelitian akan semakin baik.

\section{DAFTAR PUSTAKA}

Agus, Sartono. (2008). Manajemen Keuangan : Teori dan Aplikasi. Yogyakarta : BPFE

Amin, Widjaja Tunggal. (2009). Akuntansi Manajemen. Harvindo, Jakarta.

Anthony, N. Robert dan Govindarajan, Vijay. (2011). Sistem Pengendalian Manajemen. Jilid 2. Tanggerang: Karisma Publishing Group.

Anthony, R., Hawkins, David F., and Kenneth A. Merchant. (1999). Accounting: Text and Cases. Edition 10. Singapore: McGraw-Hill Companies, inc.

Borg, W.R., Gall, M.D. (1989). Educational Research : An Introduction. New York: Longman.

Brigham, Eugene F. dan Houston, Joel F. (2011). Dasar-dasar Manajemen Keuangan Terjemahan. Edisi 10. Jakarta: Salemba Empat.

Darsono, Azhari. (2005). Pedoman Praktis Memahami Laporan Keuangan. Andi. Yogyakarta.

Earl K. Stice, James D. Stice and Skousen. (2004). Akuntansi Intermediate, Penerbit Selemba Empat, Jakarta.

Eisenhardt, K.M., (1989). "Agency Theory: An Assessment and Review". Academy of Management Review, Vol. 14 (1). Pp. 57-74.

Garrison, Ray H., Eric W Noreen., \& Peter C Brewer. (2006). Akuntansi Manjerial. Buku 1. Edisi 11. Diterjemahkan oleh: Nuri Hinduan. Jakarta: Salemba Empat.

Gaspersz, Vincent.(2008). Total Quality

Management. PT. Gramedia Pustaka Utama, Jakarta.

Ghozali, Imam.2016. Aplikasi Analisis Multivariete Dengan Program IBM SPSS 23. Badan Penerbit Universitas Diponogoro. Semarang.

Hansen, Don R., \& Maryane M Mowen. (2006). Akuntansi Manajemen. Jilid 1. 
Edisi 7. Diterjemahkan oleh: Dewi Fitriasari dan Deny Arnos Kwary. Jakarta: Salemba Empat.

Harahap, Sofyan Syafri. (2005). Analisis Kritis atas Laporan Keuangan. Jakarta: PT Raja Grafindo Persada.

Jensen, Michael C. dan Meckling. William H. (1976). "Theory of the firm: Managerial behavior, agency costs, and ownership structure" Journal of finance economics, vol.3, no.4.

Kasmir. (2017). Analisis Laporan Keuangan. Jakarta: Raja Grafindo Persada.

Lestari, Endah dan muhammad, Mahdi. (2014). Pengaruh Biaya Kualitas terhadap Tingkat Penjualan. Jurnal Ilmiah Manajemen dan Akuntansi Fakultas Ekonomi 2014.

Mahsun, Mohammad. (2009). Pengukuran Kinerja Sektor Publik. Edisi 3. BPFE, Yogyakarta.

Martusa, R, dan Darmadi, H. (2011). Peranan Analisis Biaya Kualitas Dalam Meningkatkan Efisiensi Biaya Produksi. Jurnal Ilmiah Akuntansi, Nomor 04 tahun ke-2 Bulan Januari-April.

McClave, dkk. (2015) Statistik Untuk Bisnis dan Ekonomi. Erlangga. Jakarta

Mulyadi. (2010). Akuntansi Biaya. Penerbit dan Percetakan Sekolah Tinggi Ilmu Manajemen YKPN. Yogyakarta.

Munawir S. (2002). Analisis Laporan Keuangan. Yogyakarta: Liberty

Nazir, Moh. (2005). Metode Penelitan. Cetakan Pertama. Penerbit Ghalia Indonesia. Jakarta.

Sandag, Ester; Jantje, Taniontong dan Stanley, Kho. (2014). Analisis Biaya Kualitas Dalam Meningkatkan Profitabilitas Perusahaan. Jurnal EMBA ISSN 23031174. Vol. 2 No. 2 Juni 2014.

Santoso, Singgih. (2012). Panduan Lengkap Spss Versi 20. Jakarta: PT Elex Media. Komputindo.

Sitanggang, Fentri (2010). Pengaruh Biaya Kualitas Terhadap Tingkat Profitabilitas Perusahaan. Jurnal Ilmiah Akuntansi,
Nomor 02 Tahun ke-1 Bulan MeiAgustus.

Subramanyam. K. R and John J. Wild. (2014). Analisis Laporan Keuangan. Selemba Empat, Jakarta.

Sugiyono. (2010). Metode Penelitian Bisnis. Bandung: Alfabeta.

Sunjoyo, dkk. (2013). Aplikasi SPSS untuk Smart Riset, Bandung: Alfabeta.

Tjiptono, Fandy, dan Anastasia Dian. (2003). Total Quality Manajement. Yogyakarta: Andi.

Uma Sekaran, R. B. (2017). Research Methods For Business. United Kingdom: Jhon Willey \& Sons Ltd.

William, K Carter., \& Milton F Usry. (2006). Akuntansi Biaya. Buku 1. Edisi 13. Diterjemahkan oleh: Krista. Jakarta: Penerbit Salemba Empat.

Winarto, Heri. (2015). Analisis Pengaruh Biaya Kualitas Terhadap Tingkat Keuntungan Perusahaan. Jurnal Moneter. Vol. 11 No. 2 Oktober 2015. 